By

Mofreh F, Saleh

University of Canterbury

Department of Civil Engineering

Mofreh.saleh@canterbury.ac.nz

Tel. 643-3642987

Fax: 643-3642758 


\title{
EFFECT OF RHEOLOGY ON THE BITUMEN FOAMABILITY AND MECHANICAL PROPERTIES OF FOAM BITUMEN STABILISED MIXES
}

\begin{abstract}
The use of foamed bitumen stabilization technique is growing steadfastly and it is gaining wide spread acceptance in many different countries. This technique is new to New Zealand and it just has started to achieve some acceptance within the highway construction industry.

In the first part of this work, bitumens from seven different bitumen sources were collected and examined. Three sources that are currently used in New Zealand, three bitumens are from three sources in California in the United States, and one source is imported from Australia. The physical properties of bitumens such as penetration, viscosity and softening point, in addition to foamability tests were carried out on these bitumens samples in order to examine the effect of bitumen source, grade and bitumen rheology on the characteristics of the resulting foam.
\end{abstract}

Mixes with similar gradation were prepared with the foam bitumen resulting from the different grades and sources were subjected to resilient modulus tests to examine the mechanical properties, temperature and moisture susceptibility. It was proved that the use of temperature susceptible binders does not have a direct effect on the foaming properties. However, the resulting mixtures are likely to be sensitive to temperature change. Temperature susceptibility of foamed stabilised mixes is lower than that of the HMA. Foamed stabilised mixes exhibited a significantly improved moisture resistance as the mixes kept their integrity and strength and they did not deteriorate significantly, even after 5 days of continuous soaking in water. The average index of retained stiffness (IRS) value of $86 \%$ was observed which is reasonably high and comparable with that recommended for the HMA mixes. Indirect tensile strength, fracture energy and fatigue life were examined and compared with HMA.

KEYWORDS: foamed bitumen, rheological properties, temperature and moisture susceptibility, mechanical properties

\section{INTRODUCTION}

Rheology involves the study and evaluation of the deformation and flow of the timetemperature dependent materials, such as bitumen, that are stressed or subjected to an applied force. As discussed by Roberts et al. (1991), rheological properties of bitumen consist of age hardening, temperature susceptibility, shear susceptibility, stiffness, penetration, ductility, and viscosity. The effect of bitumen viscosity or penetration on foaming potential is not entirely clear. Abel (1978) reported that bitumen of low viscosity produced higher expansion ratios and longer half-lives than bitumen of high viscosity, but the use of high viscosity bitumen resulted in superior aggregate coating. It was also found that the presence of anti-stripping agents (surface active agents) intensified the foaming ability of the bitumen and that acceptable foaming was only achieved at temperatures above $149^{\circ} \mathrm{C}$. 
Foam bitumen is usually characterised in terms of its expansion ratio (ER) and halflife $\left(\tau_{1 / 2}\right)$ (Ruckel et. al., 1983). The expansion ratio is the ratio of the maximum measured volume of the foamed bitumen to the original volume of bitumen. High expansion ratio values give low viscosity foam that disperses well into the mix. Half-life $\left(\tau_{1 / 2}\right)$ is the time in seconds it takes for the foamed bitumen to settle to half of its maximum attained volume. Long half-lives allow more time for the mixing process. ER and $\tau_{1 / 2}$ are inversely related. Increasing the amount of foaming water increases ER and decreases $\tau_{1 / 2}$. An optimum water content that optimises both parameters can be determined. For practical applications, an ER of value greater than 10 and a $\tau_{1 / 2}$ greater than 10 seconds are recommended according to the South African Interim Technical Guidelines (TG2) (Asphalt Academy, 2002). A Foam Index (FI) has been suggested recently as a more useful measure of bitumen foaming characteristics, which takes into account both ER and $\tau_{1 / 2}$ by measuring the area under ER decay curve (Jenkins et. al., 1999). Foaming characteristics are affected by bitumen type, grade and additives; in particular, anti-foaming agents are often added to bitumens produced by solvent precipitation processes.

This present study places the emphasis only on temperature susceptibility, penetration, viscosity and softening point as they are closely related. Due to the sudden change of bitumen temperature upon its contact with cold water in the foaming process, the temperature susceptibility might have an effect on the foamability and the quality of the produced foam. Temperature susceptibility is defined as the rate at which the consistency of bitumen changes with a change in temperature. Three approaches to characterise this property are Penetration Index (PI), Penetration-Viscosity Number (PVN), and Viscosity-Temperature Susceptibility (VTS) (Roberts et al. 1991). Low PI, low PVN, and high VTS values are indicators of a binder that is highly susceptible to temperature changes (i.e. high temperature-susceptibility) and vice versa (i.e. indicating the bitumen has lower temperature susceptibility).

Both penetration and viscosity were carried out at different temperatures to investigate the temperature susceptibility of the bitumens from different sources in order to explain the effects of bitumen rheological properties on the bitumen foaming characteristics and the properties of the resulting mixtures. The study examined the relationship between the physical properties of the bitumen and the foamability characteristics of the resulting foam.

The results of bitumen consistency and bitumen foaming tests of the collected samples are presented in the following paragraphs. The results obtained from these tests were correlated to investigate the significance of rheological properties of bitumen on foaming characteristics and the behaviour of the foam-stabilised mixes, as will be discussed later in this paper.

\section{PHYSICAL PROPERTIES OF BITUMEN SAMPLES}

Table 1 summarises the physical properties of the bitumen samples. Unaged bitumens from seven different bitumen sources were collected and examined in this 
study. Five bitumens were obtained from three sources (SHL, VEN, and DLT, with different penetration grades) that are currently used in New Zealand, three were from three sources in California in the United States (AR2000, AR4000-1, and AR40002), and one (C170) from Australia.

Table 1

The sources of the New Zealand samples are denoted by letters, and the grades are indicated by numbers $(80,180)$ using the penetration grade system. Thus, the five samples are SHL80, SHL180, VEN80, VEN180, and DLT80.

Samples from the US are graded with the "Aged Residue" (AR) method. The numerical values of this grading system describe the viscosity (in poises) of these samples at $60^{\circ} \mathrm{C}$ after being aged in the Rolling Thin Film Oven (RTFO) test. Thus, the three US samples are AR2000, AR4000-1, and AR4000-2.

For the Australian bitumen, the numerical value of C170 is the viscosity of the original bitumen (in Pa.s) measured at $60^{\circ} \mathrm{C}$.

Table 1 lists the penetration and viscosity values measured at different temperatures, and the softening points of all the samples. Each test result shown in Table 1 is an average of three replicates except the softening point is an average of two replicates.

\section{Temperature Susceptibility of the Bitumen Samples}

Three approaches were used to characterise the temperature susceptibility of the bitumen from the different sources: Penetration Index (PI), Penetration-Viscosity Number (PVN), and the Viscosity-Temperature Susceptibility (VTS). The detailed results and analysis can be found in Saleh (2004). Table 2 shows the fitted penetration and viscosity with temperature. Both the standard error (S) and correlation coefficient ( $\mathrm{r}$ ) values confirm that the fitted lines are valid as the correlation coefficients are quite close to 1 (one).

Table 2

\section{Penetration Index (PI)}

The Penetration Index (PI), one of the above mentioned three methods for characterising temperature susceptibility, can be determined by drawing the relationship between penetration values on a log scale and the corresponding temperatures on an arithmetic scale. Based on the slope (gradient) of the penetrationtemperature fitted line, the Penetration Index (PI) of each sample was calculated using Equation 1. The results are shown in Table 3 and depicted in Figure 1.

$$
P I=\frac{20-(500 \times \text { slope })}{1+(50 \times \text { slope })}
$$

Equation 1 Table3 
Figure 1 shows that the PI values are between -2.08 and +0.65 . According to Roberts et al. (1991), PI values for most good paving binders are between +1 and -1 . High temperature susceptibility occurs when the binder has PI below -2 . AR2000 shows the lowest PI value while VEN80 exhibits the highest PI. Therefore, AR2000 is the most temperature-susceptible binder. Such a binder is vulnerable to brittleness, leading to cracks in cold climate areas and prone to rutting at high temperatures. In addition, those binders also have low viscosity at $135^{\circ} \mathrm{C}$ leading to tender mix problems (such as instability leading to distortion and rutting) during compaction under traffic loads (Roberts et al. 1991). Table 3 also shows that all New Zealand bitumens, except SHL180, have reasonably low temperature susceptibilities.

\section{Penetration-Viscosity Number (PVN)}

This second method is based on penetration at $25^{\circ} \mathrm{C}$ and viscosity at either $135^{\circ} \mathrm{C}$ or $60^{\circ} \mathrm{C}$, which are standard specifications for paving bitumen. Equation 2 was used to calculate PVN of each bitumen sample (Roberts et al. 1991):

where:

$$
P V N=\frac{L-X}{L-M}(-1.5)
$$

Equation 2

$\mathrm{X}=$ the logarithm of viscosity in centistokes measured at $135^{\circ} \mathrm{C}$

$\mathrm{L}=$ the logarithm of viscosity at $135^{\circ} \mathrm{C}$ for a PVN of 0.0

$\mathrm{M}=$ the logarithm of viscosity at $135^{\circ} \mathrm{C}$ for a PVN of -1.5

The values of $\mathrm{L}$ and $\mathrm{M}$ can be determined using the equations below (based on the least square fits).

The equation for the line representing a PVN of 0.0 is:

$$
\mathrm{L}=\log \left(\mathrm{Vis} @ 135^{\circ} \mathrm{C}\right)=4.258-0.7967 * \log \left(\text { Pen at } 25^{\circ} \mathrm{C}\right) \quad \text { Equation } 3
$$

The equation for the line representing a PVN of -1.5 is:

$$
\mathrm{M}=\log \left(\mathrm{Vis} @ 135^{\circ} \mathrm{C}\right)=3.46289-0.61094 * \log \left(\text { Pen at } 25^{\circ} \mathrm{C}\right) \quad \text { Equation } 4
$$

Note that this study assumed a specific gravity of all bitumen samples equal to 1 (one). The relationship between viscosity units is therefore:

1 centipoise $=1 \mathrm{mPa} . \mathrm{s}=$ centistokes $*$ bitumen specific gravity.

Table 4 shows the values of $\mathrm{X}, \mathrm{L}$, and $\mathrm{M}$. Figure 2 shows PVN values of all nine different bitumen types.

Table 4

Figure 2 
Figure 2 shows that all PVN values were between +0.05 and -2.17 . According to Roberts et al. (1991), most paving binders have a PVN between +0.5 to -2.0 . Bitumen class C170 showed the lowest PVN value, while VEN80 exhibited the highest. Thus, C170 is the most temperature-susceptible binder and VEN80 is the least temperature-susceptible bitumen. It is also clear that bitumens used in New Zealand have lower temperature susceptibility compared to US bitumens, as all the three US types lay within the high temperature-susceptibility range.

\section{Viscosity-Temperature Susceptibility (VTS)}

The Viscosity-Temperature Susceptibility (VTS) value for measuring temperature susceptibility for any particular bitumen sample was determined using the following equation:

where:

$$
\text { VTS }=\frac{\log \left(\log V \text { is at } T_{2}\right)-\log \left(\log V \text { is at } T_{1}\right)}{\log T_{1}-\log T_{2}} \quad \text { Equation } 5
$$

$$
\mathrm{T}=\text { the bitumen temperature in degrees Kelvin }\left({ }^{\circ} \mathrm{K}=273+{ }^{\circ} \mathrm{C}\right) .
$$

Table 5 was then constructed and portrayed in Figure 3.

Table 5

Figure 3 shows that all VTS values are between 4.60 and 8.80 . C170 bitumen shows the highest value, while SHL180 exhibits the lowest. Thus, C170 is the most temperature-susceptible bitumen. Figure 3 also shows that all New Zealand bitumens have reasonably low temperature susceptibilities according to their VTS values. Once again, US bitumens show high temperature susceptibility, with AR4000-1 being the worst according to its VTS value.

Each of the above three approaches used to determine the temperature susceptibility resulted in a different order of the least and the most temperature-susceptible bitumens. Nonetheless, results from the three methods show that the C170 and US bitumens have higher temperature susceptibilities compared to the New Zealand bitumens. The differences between the results of the three approaches may be attributed to the empirical nature of the penetration test. Later in this study, the temperature susceptibility of the different binders will be compared with the characteristics of the resulting foamed bitumens and will be examined against the temperature susceptibility of the resulting foam-stabilised mix.

\section{TESTS TO CHARACTERISE BITUMEN FOAMS}

In evaluating the foam characteristics, the expansion ratio (ER) and half life (HLT) values were used. Table 6 contains the foaming parameters (i.e. Expansion ratio (ER), Half Life (HLT), and Foam Index (FI)) and the results of all bitumen types used in this study. Each value shown in Table 6 is an average of three replicates. The foam index (FI) was calculated from Equation 6 (Jenkins et al. 1999): 
$F I=\frac{-\tau_{1 / 2}}{\ln 2} *\left(4-E R-4 * \ln \left(\frac{4}{E R}\right)\right)+\left(\frac{1+c}{2 c}\right) * E R * t_{s} \quad$ Equation 6

where:

$\mathrm{t}_{\mathrm{s}}=$ discharge time (in seconds): in this research, $\mathrm{t}_{\mathrm{s}}$ value is 5 seconds.

$\mathrm{c}=$ ratio of measured and actual ER; this can be determined from the

relevant chart in the South African (SA) Interim Technical Guidelines (TG2) (Asphalt Academy 2002).

Table 6

Figure 4 shows the relationship between the percentages of foamant water and the corresponding FI values for different bitumen sources. The water content that maximises the FI is the optimum foamant water content. As it appears from Figure 4, most of the bitumen sources do not show any peak. In this case, the percentage of water that generated a half-life equal to or greater certain arbitrary value that chosen based on the researcher's experience was considered the optimum. In this research a half life time equals to or greater than 7 seconds was selected to optimise the foamant water content. Table 7 gives the optimum percentage of foamant water of each sample that was used later in the preparation of foam-stabilised specimens. In addition, the FI values for the corresponding optimum foamant water are presented and subsequently the quality of resulting foam assessed for cold mix use (based on TG2, Asphalt Academy 2002).

Table 7

\section{CLASSIFICATIONS OF FOAM BITUMEN QUALITY}

Figure 4 shows that the use of the FI to optimise the percentage of foamant water is not achievable in most tests because very few bitumen types show a peak. This may be attributed to the fact that the FI was developed assuming that the rate of decay of the foam follows a certain exponential decay curve (Equation 6), which may not be valid for all bitumen types. In addition, the FI value relies on the expansion ratio and the half-life, which are both empirical parameters. Therefore, FI is also an empirical parameter. Because of the empirical nature of the current parameters that are in use to characterise the foam quality, several discrepancies in classification of the different sources of foam bitumen can be detected. For example, although DLT80, SHL80 and AR4000-2 were classified as poor or unsuitable for foam stabilisation (Table 7), they both mixed and dispersed effectively with the aggregate matrix in the laboratory without any problems. However, C170 did not mix. Due to these discrepancies, the researcher proposed a new approach to classify the foam quality (Saleh, 2004).

Table 7

According to Figure 4, VEN180 provides the best quality foam and C170 gives the lowest quality foam. It was not possible to mix the foam created from C170 since the foam formed clots and strings, therefore, no specimens could be prepared for it.

Examining Table 7, the optimum percentage of foamant water for each sample is within the range of 1 to 3.5 that was recorded in the literature (Maccarrone et al. 1994, Mohammad et al. 2003, Ramanujam \& Jones 2000). Under the same testing conditions, the effect of bitumen source is also obvious. For instance, AR4000-1 and AR4000-2 are supposed to have similar physical properties and yet they have different foamability parameters. 


\section{PHYSICAL PROPERTIES OF BITUMEN AND ITS FOAMABILITY RELATIONSHIP}

All nine bitumen types were sorted in ascending order based on their viscosity at $135^{\circ} \mathrm{C}$, and are shown in Table 8 . Generally, soft binders, except C170, produced reasonable foam, and harder binders such as AR4000-2, SHL80 and DLT80 produced low quality or unsuitable foams, according to the current TG2 classification system.

Table 8

Based on temperature susceptibly and foam classification results shown in Tables 4 and 7, respectively, Table 9 was constructed. The table lists each sample from the least to the most temperature susceptible bitumen, based on the PVN approach, and the corresponding foam classification.

Table 9

It is obvious that C170 is the most temperature-susceptible binder and produces unacceptable foam, while AR2000, which is also highly temperature-susceptible, shows reasonable foaming characteristics that were similar to those produced by VEN80 (which is the least temperature-susceptible binder). The conclusion is that the use of temperature-susceptible binders does not have a direct effect on the foaming properties. However, it is not clear how foaming properties will influence mixture behaviour. This will be assessed later in this research. 


\section{PREPARATION}

In this research, two aggregate gradations were used, which are the upper limit of the gradation band of the AP-40 (all passing the $40 \mathrm{~mm}$ sieve) and the mid-point of AP20 (all passing the $20 \mathrm{~mm}$ sieve) gradation curve. These two gradations are commonly used as base courses in New Zealand. They are reasonably close to the mid-point of the ideal zone for foamed bitumen mixes, as shown in Figure 5 and discussed in a previous study by Saleh and Herrington (2003). Figure 5 shows three zones A, B, and C. Only gradations that comply with zone A are suitable for foam bitumen stabilisation. Gradations close to B or C need to be modified to comply with zone A (Saleh, and Herrington, 2003).

Figure 5

Four types of mineral fillers: fly ash type C, pond ash, hydrated lime, and Portland cement were used to adjust the amount of fines. The Portland cement was used at $1.0 \%$ and $2.0 \%$ with fly ash type C.

Pond ash is a by-product of power generation boilers located in the Huntly region in New Zealand. This pond ash can cause an environmental hazard because of its alkalinity, high concentrations of boron, and presence of several heavy metals such as arsenic and cadmium. Using it in foam stabilisation was investigated as a potential safe way of discarding it economically.

Different combinations of AP-40, AP-20, and the mineral fillers were investigated. The name of each mix combination was designated with letters and numbers to indicate the aggregate gradation, the types of filler, and the percentage of Portland cement, if any. For example, M20FA indicates that the mix contains AP-20 gradation with fly ash as mineral filler, while M20FA2C is a mix containing AP-20 gradation, fly ash, and $2.0 \%$ Portland cement.

Two mold sizes $100 \mathrm{~mm}$ and $150 \mathrm{~mm}$ diameters were used to prepare the required briquettes. The $100 \mathrm{~mm}$ diameter was used to prepare specimens made of AP20 aggregate and the $150 \mathrm{~mm}$ was used for AP 40 aggregate. The 150-mm diameter specimens were prepared in accordance with Australian Standards AS 2891.2.2 using AP-40 aggregate, 80 gyration cycles, $540 \mathrm{kPa}$ air pressure and a $3^{\circ}$ gyratory angle (Australian Provisional guide, 2002). The 100-mm-diameter specimens were prepared using AP-20 aggregate, 80 gyration cycles, $240 \mathrm{kPa}$ air pressure, and $2^{\circ}$ gyratory angle.

\section{OPTIMUM MIXING MOISTURE AND MIXING FOAM CONTENTS}

The approach of using simultaneous determination of optimum mixing moisture content (OMMC) and optimum mixing foam content (OMFC), which was discussed in Saleh and Herrington (2003) and Saleh M. (2004), was used. It should be noted that the mixing and compaction moisture contents are the same as the specimens are compacted directly after mixing and therefore it is assumed that there is no loss of the moisture content during compaction.

In this approach, several stabilised mix specimens were prepared at different combinations of water and foam contents. Specimens were cured at room temperature for 7 days and then oven dried at $40{ }^{\circ} \mathrm{C}$. The resilient modulus of each 
combination (two replicates at the same combination) was determined for the completely dry specimens. The resilient moduli are plotted versus foam and water contents (See Figure 6). The combination of water and foam content that maximises the resilient modulus is considered the optimum mixing moisture content (OMMC) and optimum mixing foam content (OMFC). Figure 6 is just an example of the procedure used for a mix made of AP 40 aggregates and contains pond ash as mineral fillers (M40PA). The optimum mixing foam content for this particular mix shown in Figure 6 is 3.55\% and the optimum mixing water content is 6.75\%. This M40PA mix showed a low resilient modulus compared to other mixes because it has none active filler (Pond Ash). Figure 6

\section{MECHANICAL PROPERTIES OF FOAM-STABILISED MIXES}

After determining the optimum mixing moisture content (OMMC) and the optimum mixing foam content (OMFC), several specimens were prepared at these optimum values to test their mechanical properties. The properties that were analysed for these mixes are resilient modulus, temperature susceptibility, moisture susceptibility, indirect tensile strength, fracture energy, fatigue life, and CBR. The details of the CBR test are not shown here because of the paper length limitations. A summary of the indirect tensile, fracture energy and fatigue tests is briefly discussed in the following subsections.

\section{Effect of Source and Grade on Temperature Susceptibility}

Table 10 lists the resilient modulus values of foam stabilised specimens measured at different temperatures. Figure 7 shows comparisons between the different mixes. In correlation with results of temperature susceptibility of bitumen (Table 1 and Figure 2), the PVN approach closely corresponds to the temperature susceptibility properties of foamed bitumen mixtures. Table 10

The VEN80 and VEN180 bitumens were classified as yielding the least temperaturesusceptible bitumens (Figure 2) and their foamed stabilised mixes showed the least temperature-susceptible mixes, as shown in Figure 7. However, there are still some discrepancies. One example is AR-2000, which was classified as one of the most temperature-susceptible binders (Figures 1 and 2), yet it yielded mixtures that were not very temperature-susceptible as shown in Figure 7.

Figure 7

\section{Temperature Susceptibilities of Foam-stabilised and HMA Mixes}

The indirect resilient modulus test was also carried out on another mix, an AC10 (maximum nominal aggregate size is $10 \mathrm{~mm}$ ) dense-graded HMA (hot mix asphalt) produced from SHL80. The resilient modulus test was conducted on the HMA at $15^{\circ}$, $20^{\circ}$, and $25^{\circ} \mathrm{C}$. The maximum temperature of the test was limited to $25^{\circ} \mathrm{C}$ so that the HMA specimen was kept in the desired temperature and loading range within which it will retain its elastic behaviour. Figure 8 shows a comparison between the AC10 HMA and the foam-stabilised mix (M20FA1C) produced from the same source and grade of bitumen (SHL80). 
Clearly, the resilient modulus of the HMA undergoes a higher decrease at elevated temperatures while the foam-stabilised mix still maintains high resilient modulus value. This finding agrees with Bissada (1987). Muthen (1999) attributes the high resilient modulus values of foam-stabilised mixtures at high temperatures to the preservation of the friction between the larger particles because they are not coated with binder, even though the bitumen-fines mortar in a foamed bitumen mixture will soften with increasing temperature. In addition, HMA contains a high bitumen content (about 5.5\%) compared to the foam-stabilised mixes, which usually contain only up to 3.0 to $3.5 \%$ binder content. This high bitumen content will cause the HMA to be more temperature-susceptible compared to foam-stabilised mixes. This indicates that foam-stabilised mixes are likely to suffer much less distortion and rutting compared to the HMA in areas where the pavement temperature is expected to be quite high on hot summer days.

\section{Effect of Source and Grade on Moisture Susceptibility}

Table 10 lists the resilient moduli and index of retained stiffness (IRS) values. The IRS is defined as the percentage of the resilient modulus after soaking to the resilient modulus value before soaking. To measure the IRS values, the resilient moduli of the dry specimens (three replicates per test) were first measured, and then specimens were subjected to five days soaking. The resilient moduli were measured every 24 hours. Figure 9 shows the IRS values for the eight different types of bitumens over different soaking periods. AR4000-1 shows the highest IRS values while AR4000-2 provides the lowest IRS values. The average IRS value for all types over the five days soaking period exceeded $86 \%$, which is a reasonable value.

Table 10

\section{Figure 9}

Figure 9 shows no exact pattern concerning the susceptibility of the specimens to moisture. Instead, a scattered pattern was found for different soaking periods, which might be due to the repeatability of the resilient modulus test. These variations also might be attributed to the change of the specimens strength as the active mineral fillers (i.e. cement, lime, or fly ash type $\mathrm{C}$ ) react with water over the soaking period resulting in higher strength. In the meanwhile, some deterioration in the bond between bitumen and aggregates will occur due to the weakening of the mix and stripping of bitumen. The resultant effect of these two actions will change over time causing such fluctuation with the IRS value.

\section{Indirect Tensile Strength and Fracture Energy}

The indirect tensile strength (ITS) and fracture energy tests were carried out at $23{ }^{\circ} \mathrm{C}$ for different foam-stabilised mixes and was compared with that for HMA. HMA provided high ITS (about $1198 \mathrm{kPa}$ ) and high fracture energy (13.9 kN.mm) values which is about three times that of the foam-stabilised mixes. The effects of gradation and the type of mineral fillers were quite noticeable, as active fillers such as fly ash 
type C and Portland cement noticeably improved the ITS and fracture energy values for foam-stabilised mixes.

\section{Fatigue Life}

The use of foam bitumen to stabilise unbound granular materials will transform these materials to bound materials. Also because of the high stiffness values for these mixes, they are likely to arrest high stress concentrations; therefore, fatigue cracking will be a significant form of distress in these materials. The Nottingham indirect fatigue test was used to measure the fatigue life of foam-stabilised mixes (Read and Brown 1996).

The specimen is loaded diametrically with a vertical compressive force. This indirectly generates a tensile stress across the vertical diameter. The test was run in the stress controlled mode and the failure is defined when the specimen was split or the vertical deflection reach $9 \mathrm{~mm}$ as defined by Read and Brown (1996). In all specimens tested, a clear direct split was observed before the vertical deformation reaches the $9 \mathrm{~mm}$ threshold. For any stress level specified by the operator, the magnitude of the applied compressive force and the corresponding horizontal tensile strain can be calculated by Equations 7 and 8 .

$$
\begin{array}{ll}
\mathrm{P}=\frac{\sigma_{\mathrm{xmax}} * \pi * \mathrm{~d} * \mathrm{t}}{2} & \text { Equation 7 } \\
\varepsilon_{x \max }=\frac{\sigma_{x \max }}{S_{m}}(1+3 * v) * 1000 & \text { Equation 8 }
\end{array}
$$

where:

$$
\begin{array}{ll}
P & =\text { Vertical compressive force }(\mathrm{kN}) \\
\sigma_{\mathrm{xmax}} & =\text { Maximum horizontal tensile stress }(\mathrm{kPa}) \\
\varepsilon_{x \max } & =\text { Maximum horizontal tensile strain }(\mu \varepsilon) \\
v & =\text { Poisson's ratio } \\
d & =\text { Diameter of the specimen }(\mathrm{m}) \\
t & =\text { Thickness of the specimen (m) } \\
S_{m} & =\text { Stiffness modulus (resilient modulus) of the specimen (MPa) }
\end{array}
$$

\section{Fatigue Models for Foamed Bitumen-Stabilised Mixes}

Equations 9 and 10 are the two forms of fatigue models developed for M20FA1C mixes (mixes made of AP20 aggregate with fly ash and $1.0 \%$ cement as mineral fillers). Figure 10 illustrates the goodness of fit of the model shown in Equation 10. Figure 11 shows a comparison between the fatigue life of AC10 HMA, open-graded porous asphalt (OGPA) and foam-stabilised mix M20FA1C. All materials were tested by the indirect tensile fatigue test in a controlled stress mode. It is obvious that HMA has a much higher fatigue life compared to foam-stabilised mixes when they are compared at the same tensile strain level. This finding agrees with the indirect tensile strength values and fracture energy discussed before. The high fatigue life of the HMA can be attributed to the high binder content, and the good homogeneous coating of bitumen on all aggregate particles that provide flexibility to the mix.

$N_{f}=7.67 * 10^{-3} * \varepsilon^{-1.2207}$

$R^{2}=0.979$ 
$N_{f}=0.3208 * \varepsilon^{-2.525} * M_{r}^{-1.9256}$

$R^{2}=0.996$

Figure 10 and Figure 11

In Figure 11, the slopes of the fatigue curves of the OGPA and the foam-stabilised mixes are steeper than that of the HMA. This clearly indicates that the fatigue performance of these mixes is inferior to that of the HMA mixes.

In the design of the foam-stabilised mixes, the optimum foam and water content were determined so that the resilient modulus of the mix will be maximised with no regard for fatigue life. Therefore, it is recommended to include some parameters such as indirect tensile strength or fracture energy in the mix design procedure. Thus, the foam, water content, and the ratio between foam and mineral fillers content should be determined to optimise the value of ITS or fracture energy. This will ensure longer fatigue life for these mixes.

\section{CONCLUSIONS}

The temperature susceptibilities of the different types of bitumen were investigated, as well as those of the mixes. Using bitumen that has low temperature susceptibility generally produced foamed-stabilised mixes that also had low temperature susceptibilities. However, some bitumens with high temperature susceptibilities produced foam-stabilised mixes with a moderate temperature susceptibility.

The behaviour of the foamed-bitumen mixes produced from different bitumen types was measured. The experimental work presented includes the foaming characterisation of bitumens from seven sources. According to the foam index parameter, VEN180 and AR4000-1 provided the best quality foam while C170, SHL80 and DLT80 resulted in a foamed bitumen of poorest quality. The current foamability test parameters showed discrepancies in characterising the foam quality of the different types due to the empirical nature of the test. The comparison of temperature susceptibility of HMA with that of foam-stabilised mixes made with the same bitumen type showed that the HMA mixes are more sensitive to temperature variations.

The moisture susceptibility of foam-stabilised mixes, especially the effect of bitumen source and grade on moisture susceptibility as shown by the Index of Retained Stiffness (IRS), was studied. While the bitumens from some sources provided higher values of IRS than bitumens from other sources, foam-stabilised mixes, in general, provided excellent moisture resistance as their IRS exceeded $80 \%-90 \%$ after 5 days of soaking. The difference between different sources could be attributed to the different adhesion characteristics of the different sources and grades of bitumens.

Foam-stabilised mixes provided a lower fatigue life compared to HMA and OGPA. However, if the bitumen and mineral filler contents were to be optimised so that the 
indirect tensile strength or fatigue energy were maximised, then the fatigue life of these mixes could be improved.

The indirect tensile strength and fracture energy of the foam stabilised mixes were investigated and compared with that of the HMA. The HMA showed higher tensile strength and fracture energy values than that of the foam stabilised mixes.

The fatigue behaviour of the foam-stabilised mixes was investigated, as well as that of dense-graded AC10 HMA and open-graded porous asphalt (OGPA), to compare their fatigue life performance. Foam-stabilised mixes provided a lower fatigue life compared to HMA and OGPA. However, if the bitumen and mineral filler contents were to be optimised so that the indirect tensile strength or fracture energy were maximised, then the fatigue life of these mixes could be improved.

\section{Acknowledgement}

I would like to thank Transfund New Zealand for its financial support that has made this research possible.

I also would like to express my appreciation to the Department of Civil Engineering, University of Canterbury, which has provided an intellectually stimulating environment in which to work.

\section{References}

Abel F. 1978. Foamed asphalt base stabilization, $6^{\text {th }}$ Annual Asphalt Paving Seminar, Colorado State University.

Asphalt Academy. 2002. Interim Technical Guidelines: The Design and Use of Foamed Bitumen Treated Materials (TG2). South Africa.

Australian provisional guide, Selection and Design of Asphalt Mixes, APRG Report No. 18, 2002.

Bissada, A.F. 1987. Structural response of foamed asphalt sand mixtures in hot environments. Transportation Research Record 1115: 134-149. Washington DC, USA.

Jenkins, K.J., Van de Ven, M.F.C., de Groot, J.L.A. 1999. Characterisation of foamed bitumen. Proceedings $7^{\text {th }}$ Conference on Asphalt Pavements for Southern Africa (CAPSA '99): 1-18.

Maccarrone, S., Holleran, G., Leonard, D.J., Dip, S.H. 1994. Pavement recycling using foamed bitumen. Proceedings $17^{\text {th }}$ Australian Road Research Board Conference, Part 3: 349-365. ARRB Conference, Gold Coast, Queensland.

Mohammad, L.N., Abu-Farsakh, M.Y., Wu, Z., Abadie, C. 2003. Louisiana experience with foamed recycled asphalt pavement base materials. Transportation Research Board TRR 1832: 17-24. 
Muthen, K.M. 1999. Foamed asphalt mixes - mix design and procedure. CSIR Contract Report No. CR-98/077. 39pp. CSIR Transportek, South Africa.

Ramanujam, J.M., Jones, J.D. 2000. Characterisation of foamed bitumen stabilization. Proceedings Road System and Engineering Technology Forum: 1-22. Queensland, Australia.

Read, J.M., Brown, S.F. 1996. Fatigue characterisation of bituminous mixes using a simplified test. Pp. 158-172 in Proceedings of Symposium on Performance and Durability of Bituminous Materials (Cabrera, J.G., Dixon, J.R. Editors). E \& F N Spon, London.

Roberts, F.L., Kandhal, P.S., Brown, E.R., Lee, D.Y. 1991. Hot mix asphalt materials, mixture design, and construction. NAPA Educational Foundation, Lanham, Maryland, USA.

Ruckel, P.J., S.M. Acott, and R.H. Bowering, Foamed-asphalt paving mixtures: preparation of design mixes and treatment of test specimens. Transportation Research Record Number 911: 88-95, 1983.

Saleh, M.F., Herrington, P. 2003. Foamed bitumen stabilisation for New Zealand roads. Transfund New Zealand Research Report No. 250. 88pp.

Saleh, M, New Zealand experience with Foam Bitumen Stabilization, Journal of Transport Research Board, Record No 1868, 2004: 40-49

Saleh, M, , 2004, Detailed experimental investigation for foamed bitumen stabilization, Transfund New ZealandResearch Report, no 258, pp: 68 
Table 1 Results of consistency tests of the 9 bitumen types from 7 different sources.

\begin{tabular}{|c|c|c|c|c|c|}
\hline \multirow[b]{2}{*}{$\begin{array}{l}\text { Bitumen } \\
\text { Type }\end{array}$} & \multicolumn{2}{|c|}{ Penetration } & \multicolumn{2}{|c|}{ Viscosity } & \multirow[b]{2}{*}{$\begin{array}{l}\text { Softening } \\
\text { Point }\left({ }^{\circ} \mathrm{C}\right)\end{array}$} \\
\hline & $\begin{array}{l}\text { Temperature } \\
\left({ }^{\circ} \mathrm{C}\right)\end{array}$ & $\begin{array}{l}\text { Reading } \\
\text { (dmm) }\end{array}$ & $\begin{array}{l}\text { Temperature } \\
\left({ }^{\circ} \mathrm{C}\right)\end{array}$ & $\begin{array}{l}\text { Reading } \\
\text { (mPa.s) }\end{array}$ & \\
\hline \multirow{4}{*}{ SHL80 } & 20 & 60 & 80 & 17500 & \multirow{8}{*}{47} \\
\hline & 25 & 86 & 95 & 4810 & \\
\hline & 30 & 142 & 110 & 1671 & \\
\hline & & & 135 & 435 & \\
\hline \multirow{4}{*}{ SHL180 } & 15 & 52 & 80 & 7125 & \\
\hline & 20 & 97 & 95 & 2285 & \\
\hline & 25 & 169 & 110 & 864.3 & \\
\hline & & & 135 & 250 & \\
\hline \multirow{5}{*}{ VEN80 } & 20 & 53 & 80 & 27500 & \multirow{5}{*}{47.5} \\
\hline & 25 & 78 & 95 & 7150 & \\
\hline & 30 & 123 & 110 & 2290 & \\
\hline & & & 135 & 550 & \\
\hline & & & 150 & 268.8 & \\
\hline \multirow{5}{*}{ VEN180 } & 18 & 92 & 80 & 8100 & \multirow{5}{*}{38} \\
\hline & 21.5 & 129 & 95 & 2425 & \\
\hline & 25 & 187 & 110 & 925 & \\
\hline & & & 13 & 261.2 & \\
\hline & & & 150 & 150 & \\
\hline \multirow{4}{*}{ DLT80 } & 20 & 45 & 95 & 5700 & \multirow{4}{*}{45} \\
\hline & 25 & 76 & 110 & 1925 & \\
\hline & 30 & 135 & 120 & 1001 & \\
\hline & & & 135 & 427.5 & \\
\hline \multirow{9}{*}{ AR2000 } & 20 & 39 & 80 & 9550 & \multirow{5}{*}{38} \\
\hline & 25 & 74 & 95 & 2470 & \\
\hline & 30 & 141 & 110 & 780 & \\
\hline & & & 135 & 190 & \\
\hline & J & & 150 & 100 & \\
\hline & 20 & 26 & 80 & 19800 & \multirow{8}{*}{-48} \\
\hline & 25 & 43 & 95 & 4385 & \\
\hline & 30 & 80 & 110 & 1360 & \\
\hline & & & 135 & 276 & \\
\hline \multirow{4}{*}{ AR4000-2 } & 20 & 29 & 80 & 17650 & \\
\hline & 25 & 55 & 95 & 4430 & \\
\hline & 30 & 102 & 110 & 1450 & \\
\hline & & & 135 & 310 & \\
\hline \multirow{6}{*}{ C170 } & & & 60 & 121162 & \multirow{6}{*}{42.5} \\
\hline & 20 & 36 & 70 & 55500 & \\
\hline & 25 & 61 & 80 & 18300 & \\
\hline & 30 & 119 & 90 & 7162 & \\
\hline & & & 100 & 3190 & \\
\hline & & & 110 & 1563 & \\
\hline
\end{tabular}


Table 2 Fitted lines for penetration and viscosity for bitumens from different sources.

\begin{tabular}{|c|c|c|c|c|c|c|}
\hline $\begin{array}{l}\text { Bitumen } \\
\text { Type }\end{array}$ & $\begin{array}{l}\text { Penetration Fitted Lines } \\
(\text { Log pen = ) }\end{array}$ & & $r$ & $\begin{array}{l}\text { Viscosity Fitted Lines } \\
(\text { Log vis =) }\end{array}$ & & \\
\hline SHL80 & $1.02988+0.0370 * \mathrm{~T}$ & 0.025 & 0.995 & $6.3387-0.02731 * \mathrm{~T}$ & 0.107 & 0.99 \\
\hline SHL180 & $0.9271+0.05235 * \mathrm{~T}$ & 0.016 & 0.999 & $5.7515-0.02468 * \mathrm{~T}$ & 0.095 & 0.99 \\
\hline VEN80 & $0.993+0.03636 * \mathrm{~T}$ & 0.012 & 0.999 & $6.6605-0.02891 * \mathrm{~T}$ & 0.112 & 0.99 \\
\hline VEN180 & $1.1717+0.0439 * \mathrm{~T}$ & 0.006 & 1 & $5.8225-0.0250 * \mathrm{~T}$ & 0.107 & 0.99 \\
\hline DLT80 & $0.6990+0.04757 * \mathrm{~T}$ & 0.009 & 1 & $6.4265-0.02834 * \mathrm{~T}$ & 0.036 & 1.00 \\
\hline AR2000 & $0.4748+0.05580 * \mathrm{~T}$ & 0.001 & 1 & $6.1726-0.02863 * \mathrm{~T}$ & 0.124 & 0.99 \\
\hline AR4000-1 & $0.4387+0.04847 * \mathrm{~T}$ & 0.021 & 0.998 & $6.68406-0.0312 * \mathrm{~T}$ & 0.129 & 0.99 \\
\hline AR4000-2 & $0.370+0.05469 * \mathrm{~T}$ & 0.004 & 1 & $6.5306-0.02968 * \mathrm{~T}$ & 0.111 & 0.99 \\
\hline C170 & $0.51781+0.05151 * \mathrm{~T}$ & 0.025 & 1 & $7.42629-0.03905 * \mathrm{~T}$ & 0.060 & 1.00 \\
\hline
\end{tabular}


Table 3 Penetration indices (PI) of the bitumens from different sources, arranged in order of decreasing PI (lowest temperature susceptibility to the highest).

\begin{tabular}{|l|l|l|}
\hline Bitumen Type & Slope & PI \\
\hline VEN80 & 0.03636 & 0.65 \\
\hline SHL80 & 0.03700 & 0.53 \\
\hline VEN180 & 0.04390 & -0.61 \\
\hline DLT80 & 0.04757 & -1.12 \\
\hline AR-4000-1 & 0.04847 & -1.24 \\
\hline C170 & 0.05151 & -1.61 \\
\hline SHL180 & 0.05235 & -1.71 \\
\hline AR-4000-2 & 0.05469 & -1.97 \\
\hline AR-2000 & 0.05580 & -2.08 \\
\hline
\end{tabular}


Table 4 Penetration-viscosity numbers (PVN) of the nine bitumen types, arranged in order of decreasing PVN (lowest temperature susceptibility to highest).

\begin{tabular}{|l|l|l|l|l|}
\hline $\begin{array}{l}\text { Bitumen } \\
\text { Type }\end{array}$ & X & L & M & PVN \\
\hline VEN80 & 2.76 & 2.74 & 2.30 & 0.051 \\
\hline VEN180 & 2.45 & 2.45 & 2.08 & -0.011 \\
\hline SHL80 & 2.65 & 2.70 & 2.27 & -0.171 \\
\hline SHL180 & 2.42 & 2.47 & 2.10 & -0.226 \\
\hline DLT80 & 2.60 & 2.75 & 2.31 & -0.517 \\
\hline AR4000-2 & 2.52 & 2.87 & 2.40 & -1.112 \\
\hline AR4000-1 & 2.47 & 2.94 & 2.45 & -1.446 \\
\hline AR2000 & 2.31 & 2.77 & 2.32 & -1.544 \\
\hline C170 & 2.15 & 2.82 & 2.36 & -2.169 \\
\hline
\end{tabular}

Table 5 Viscosity-temperature susceptibility (VTS) of the nine bitumen types, arranged in order of increasing VTS (lowest temperature susceptibility to highest).

\begin{tabular}{|l|l|}
\hline Bitumen Type & VTS \\
\hline SHL180 & 4.60 \\
\hline VEN180 & 4.61 \\
\hline SHL80 & 4.65 \\
\hline VEN80 & 4.74 \\
\hline DLT80 & 4.94 \\
\hline AR4000-2 & 5.38 \\
\hline AR2000 & 5.70 \\
\hline AR4000-1 & 5.81 \\
\hline C170 & 8.80 \\
\hline
\end{tabular}


Table 6 Foaming properties of the nine different bitumen types.

\begin{tabular}{|c|c|c|c|c|c|c|c|}
\hline \multirow{2}{*}{$\% W_{c}$} & ER & HLT & FI & \multirow{2}{*}{$\% W_{c}$} & ER & HLT & FI \\
\hline & \multicolumn{3}{|l|}{ SHL80 } & & \multicolumn{3}{|l|}{ SHL180 } \\
\hline 2.0 & 6 & 12.7 & 40.0 & 2.0 & 5.8 & 10.4 & 37.4 \\
\hline 2.5 & 7.7 & 6.2 & 53.4 & 2.5 & 7.6 & 9.5 & 56.4 \\
\hline 3.0 & 9.7 & 4.7 & 72.8 & 3.0 & 9.3 & 8.8 & 77.3 \\
\hline 3.5 & 11 & 3.5 & 88.4 & 3.5 & 11.3 & 7.6 & 99.1 \\
\hline 4.0 & 12 & 4.0 & 93.4 & 4.0 & 13.9 & 7.2 & 130.7 \\
\hline 4.5 & 12 & 3.2 & 97.5 & 4.5 & & & \\
\hline$\% W_{c}$ & \multicolumn{3}{|l|}{ VEN80 } & $\% W_{c}$ & \multicolumn{3}{|l|}{ VEN180 } \\
\hline 2.0 & 12.0 & 10.3 & 119.7 & 2.0 & 9.7 & 23.7 & 123.5 \\
\hline 2.5 & 12.5 & 8.0 & 115.6 & 2.5 & 15.3 & 16.0 & 218.4 \\
\hline 3.0 & 13.3 & 7.5 & 124.6 & 3.0 & 18.0 & 6.3 & 176.6 \\
\hline 3.5 & 15.3 & 5.7 & 141.9 & 3.5 & 20.0 & 5.7 & 196.7 \\
\hline 4.0 & 17.7 & 4.9 & 163.5 & 4.0 & 24.0 & 5.0 & 237.9 \\
\hline 4.5 & 20.0 & 4.3 & 185.1 & 4.5 & 24.0 & 5.2 & 240.2 \\
\hline$\% W_{c}$ & \multicolumn{3}{|l|}{ DLT80 } & $\% W_{c}$ & \multicolumn{3}{|l|}{ AR2000 } \\
\hline 2.0 & 7 & 8 & 48.4 & 1.5 & 11 & 8.9 & 94.4 \\
\hline 2.5 & 10 & 3 & 78.2 & 2.0 & 12 & 10.3 & 119.9 \\
\hline 3.0 & 11 & 3 & 87.7 & 2.5 & 16 & 5.5 & 134.4 \\
\hline 3.5 & 12 & 4 & 97.0 & 3.0 & 17 & 3.6 & 127.1 \\
\hline 4.0 & 14 & 5 & 121.0 & 3.5 & 18 & 3.6 & 135.9 \\
\hline \multirow[t]{2}{*}{4.5} & 17 & 5 & 155.2 & 4.0 & 18 & 3.2 & 132.4 \\
\hline & & & & 4.5 & 19 & 3.1 & 142.2 \\
\hline$\% W_{c}$ & \multicolumn{3}{|l|}{ AR4000-1 } & $\% W_{c}$ & \multicolumn{3}{|c|}{ AR4000-2 } \\
\hline 1.5 & 11 & 23.8 & 152.2 & 1.5 & 10 & 7.3 & 69.63 \\
\hline 2.0 & 14 & 8.8 & 137.0 & 2.0 & 11 & 6 & 80.06 \\
\hline 2.5 & 17 & 5.7 & 155.3 & 2.5 & 11 & 4.7 & 77.35 \\
\hline 3.0 & 18 & 4.6 & 160.5 & 3.0 & 12 & 6.7 & 96.38 \\
\hline 3.5 & 18 & 5.2 & 168.6 & 3.5 & 13 & 6.4 & 100.3 \\
\hline 4.0 & 21 & 5.5 & 201.2 & 4.0 & 14 & 5.2 & 104.9 \\
\hline 4.5 & 23 & 5.1 & 229.4 & 4.5 & 16 & 4.6 & 121.4 \\
\hline$\% W_{c}$ & \multicolumn{3}{|l|}{ C170 } & & & & \\
\hline 2.0 & 3 & 32 & 22.1 & & & & \\
\hline 2.5 & 6 & 27.3 & 45.5 & & & & \\
\hline 3.0 & 7 & 30.4 & 68.8 & & & & \\
\hline 3.5 & 8 & 12.8 & 66.2 & & & & \\
\hline 4.0 & 9 & 9.7 & 74.5 & & & & \\
\hline 4.5 & 11 & 3.0 & 89.4 & & & & \\
\hline
\end{tabular}

Note: ER Expansion Ratio HLT

FI Foam Index

Half-life in seconds 
Table 7 Optimum foamant water content, FI, and Foam Classification* of the nine bitumen types (in order of decreasing FI, or decreasing suitability for foaming).

\begin{tabular}{|l|c|l|l|}
\hline Bitumen Type & $\begin{array}{l}\text { \% Optimum } \\
\text { Foamant } \\
\text { Water }\end{array}$ & Foam Index & $\begin{array}{l}\text { Foam } \\
\text { Classification }\end{array}$ \\
\hline VEN180 & 2.6 & 224 & Very Good \\
\hline AR4000-1 & 2 & 143.5 & Good \\
\hline AR2000 & 2 & 118.6 & Moderate \\
\hline VEN80 & 3 & 114.9 & Moderate \\
\hline SHL180 & 3.5 & 109 & Moderate \\
\hline AR4000-2 & 2 & 89.7 & Poor \\
\hline C170 & 3.5 & 66 & Unsuitable \\
\hline SHL80 & 2.5 & 55.7 & Unsuitable \\
\hline DLT80 & 2 & 48.4 & Unsuitable \\
\hline
\end{tabular}


Table 8 Relationship between bitumen viscosity at $135^{\circ} \mathrm{C}$ of the bitumen samples, and their foam quality (in order of increasing viscosity).

\begin{tabular}{|c|c|c|}
\hline \multirow{2}{*}{ Bitumen Type } & \multicolumn{2}{|c|}{ Viscosity at Foam } \\
\hline & $135^{\circ} \mathrm{C}$ (mPa.s) & Classification \\
\hline C170 & 143 & Unsuitable \\
\hline AR-2000 & 203 & Moderate \\
\hline SHL180 & 263 & Good \\
\hline VEN180 & 280 & Very Good \\
\hline AR-4000-1 & 297 & Good \\
\hline AR-4000-2 & 334 & Poor \\
\hline DLT80 & 399 & Unsuitable \\
\hline SHL80 & 449 & Unsuitable \\
\hline VEN80 & 572 & Moderate \\
\hline
\end{tabular}


Table 9 Relationship between temperature susceptibility and foaming quality (in order of decreasing PVN).

\begin{tabular}{|l|l|l|}
\hline Bitumen Type & PVN & $\begin{array}{l}\text { Foam } \\
\text { Classification }\end{array}$ \\
\hline VEN80 & 0.05 & Moderate \\
\hline VEN180 & -0.01 & Very Good \\
\hline SHL80 & -0.17 & Unsuitable \\
\hline SHL180 & -0.23 & Good \\
\hline DLT80 & -0.52 & Unsuitable \\
\hline AR4000-2 & -1.11 & Poor \\
\hline AR4000-1 & -1.45 & Good \\
\hline AR2000 & -1.54 & Moderate \\
\hline C170 & -2.17 & Unsuitable \\
\hline
\end{tabular}


Table 10 Resilient moduli $M_{\mathbf{r}}$ (in MPa) of foam stabilised specimens produced from the eight bitumen types (in order of increasing rate of change), at different temperatures.

\begin{tabular}{|c|c|c|c|c|c|c|}
\hline \multirow[b]{2}{*}{ Bitumen Type } & \multicolumn{6}{|c|}{ Resilient Modulus $\mathrm{M}_{\mathrm{r}}$ (MPa) } \\
\hline & $20^{\circ} \mathrm{C}$ & $25^{\circ} \mathrm{C}$ & $30^{\circ} \mathrm{C}$ & $35^{\circ} \mathrm{C}$ & Fitted Line Equation for $\mathrm{M}_{\mathrm{r}}$ & $\mathbf{R}^{2}$ \\
\hline SHL80 & 6335 & 4731 & 3697 & 2634 & $\mathrm{M}_{\mathrm{r}}=-247 * \mathrm{~T}+11141$ & 0.99 \\
\hline SHL180 & 7771 & 5866 & 4618 & 3068 & $\mathrm{M}_{\mathrm{r}}=-310 * \mathrm{~T}+13860$ & 0.99 \\
\hline VEN80 & 5121 & 4274 & 3557 & 3041 & $\mathrm{M}_{\mathrm{r}}=-141.6 * \mathrm{~T}+7891$ & 0.99 \\
\hline VEN180 & 4324 & 3522 & 2765 & 2024 & $\mathrm{M}_{\mathrm{r}}=-153.6 * \mathrm{~T}+7383$ & 1.00 \\
\hline DLT80 & 8539 & 6460 & 5048 & 3468 & $\mathrm{M}_{\mathrm{r}}=-336.5 * \mathrm{~T}+15133$ & 0.99 \\
\hline AR2000 & 4606 & 3626 & 2374 & 1767 & $\mathrm{M}_{\mathrm{r}}=-197.8 * \mathrm{~T}+8532$ & 0.98 \\
\hline AR4000-1 & 8616 & 5909 & 4311 & 3189 & $\mathrm{M}_{\mathrm{r}}=-369.5 * \mathrm{~T}+15669$ & 0.96 \\
\hline AR4000-2 & 4427 & 3547 & 2596 & 2011 & $\mathrm{M}_{\mathrm{r}}=-166 * \mathrm{~T}+7710$ & 0.99 \\
\hline
\end{tabular}

$\mathrm{T}=$ Temperature in ${ }^{\circ} \mathrm{C}$

$\mathrm{C} 170$ was not analysed further as it was unsuitable for foam production. 
Table 11 Resilient moduli $M_{r}$ (in MPa) and IRS values of soaked foam stabilised specimens produced from the eight bitumen types, over 5 days.

\begin{tabular}{|c|c|c|c|c|c|c|c|}
\hline \multirow{2}{*}{\multicolumn{2}{|c|}{ Bitumen Type }} & \multicolumn{6}{|c|}{ Soaking Period (hours) } \\
\hline & & \multirow{2}{*}{\begin{tabular}{|l|}
0 \\
4662 \\
\end{tabular}} & \multirow{2}{*}{$\begin{array}{l}24 \\
4756\end{array}$} & \multirow{2}{*}{48} & \multirow{2}{*}{$\begin{array}{l}72 \\
5370 \\
\end{array}$} & \multirow{2}{*}{\begin{tabular}{|l}
96 \\
4199 \\
\end{tabular}} & \multirow{2}{*}{\begin{tabular}{|l|}
20 \\
4333
\end{tabular}} \\
\hline & $\mathbf{M}_{\mathrm{r}}$ & & & & & & \\
\hline SHL80 & IRS & 100.00 & 102.0 & 81.2 & 115.2 & 90.1 & 92.9 \\
\hline \multirow{2}{*}{ SHL180 } & $\mathbf{M}_{\mathrm{r}}$ & 5438 & 5196 & 5397 & 5413 & 4769 & 5142 \\
\hline & IRS & 100.0 & 95.5 & 99.3 & 99.5 & 87.7 & 94.6 \\
\hline \multirow{2}{*}{ VEN80 } & $\mathbf{M}_{\mathrm{r}}$ & 5308 & 4800 & 4778 & 5008 & 4589 & 4582 \\
\hline & IRS & 100.0 & 90.4 & 90.0 & 94.4 & 86.5 & 86.3 \\
\hline \multirow[t]{2}{*}{ VEN180 } & $\mathbf{M}_{\mathrm{r}}$ & 3564 & 3443 & 2993 & 3242 & 3024 & 2884 \\
\hline & IRS & 100.0 & 96.6 & 84.0 & 91.0 & 84.8 & 80.9 \\
\hline \multirow[t]{2}{*}{ DLT80 } & $\mathbf{M}_{\mathrm{r}}$ & 7215 & 5637 & 5606 & 5115 & 5557 & 5519 \\
\hline & IRS & 100.0 & 78.1 & 77.7 & 70.9 & 77.0 & 76.5 \\
\hline \multirow[t]{2}{*}{ AR2000 } & $\mathbf{M}_{\mathrm{r}}$ & 3435 & 3300 & 3124 & 4253 & 3707 & 3813 \\
\hline & IRS & 100.0 & 96.1 & 90.9 & 123.8 & 107.9 & 111.0 \\
\hline \multirow[t]{2}{*}{ AR4000-1 } & $\mathbf{M}_{\mathrm{r}}$ & 5772 & 6371 & 5958 & 7876 & 6902 & 7100 \\
\hline & IRS & 100.0 & 110.4 & 103.2 & 136.5 & 119.6 & 123.0 \\
\hline \multirow[t]{2}{*}{ AR4000-2 } & $\mathbf{M}_{\mathrm{r}}$ & 4528 & 3877 & 2948 & 3383 & 3046 & 4200 \\
\hline & IRS & 100.0 & 85.6 & 65.1 & 74.7 & 67.3 & 92.8 \\
\hline
\end{tabular}




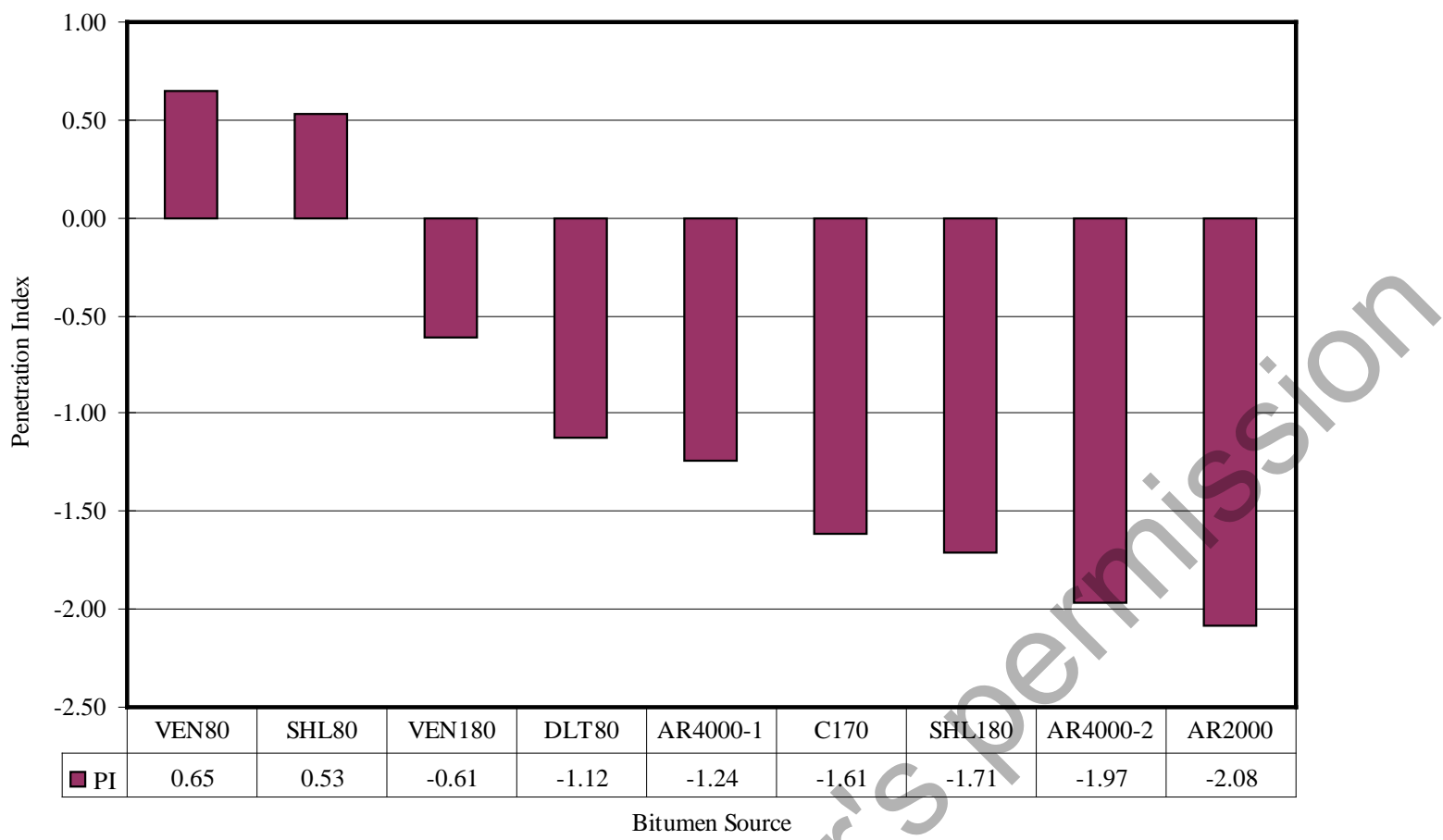

Figure 1 Penetration indices of the bitumens from different sources, shown graphically. 


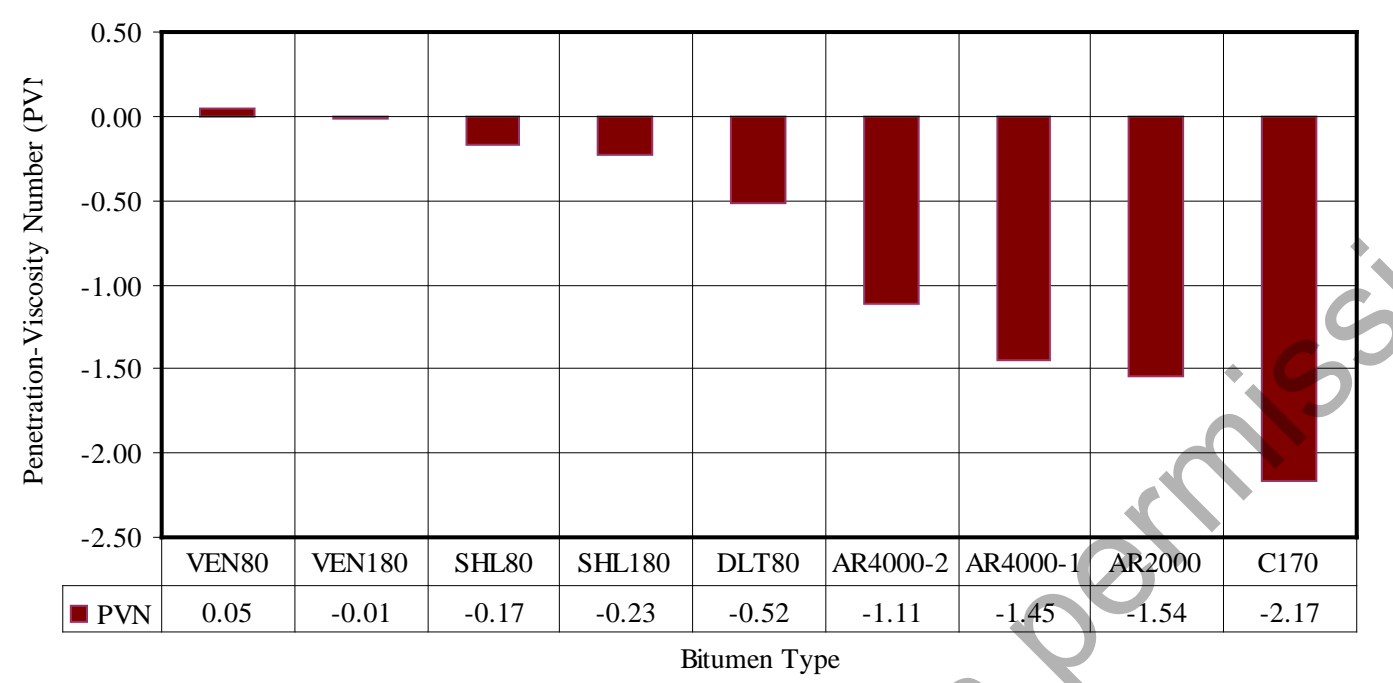

Figure 2 Penetration-viscosity numbers (PVN) of the nine bitumen types, shown graphically.

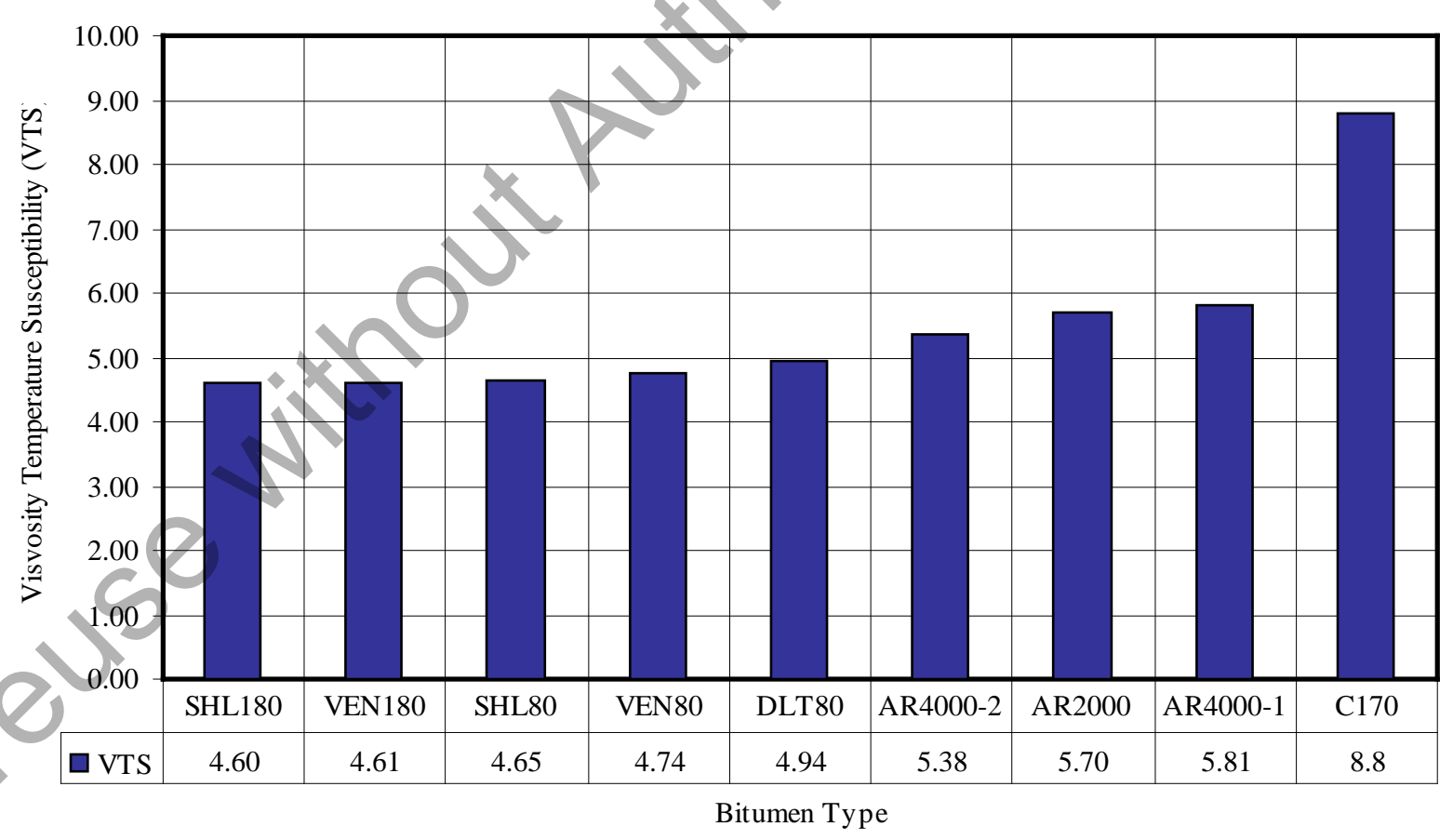

Figure 3 Viscosity-temperature susceptibility (VTS) of the nine bitumen types, shown graphically. 


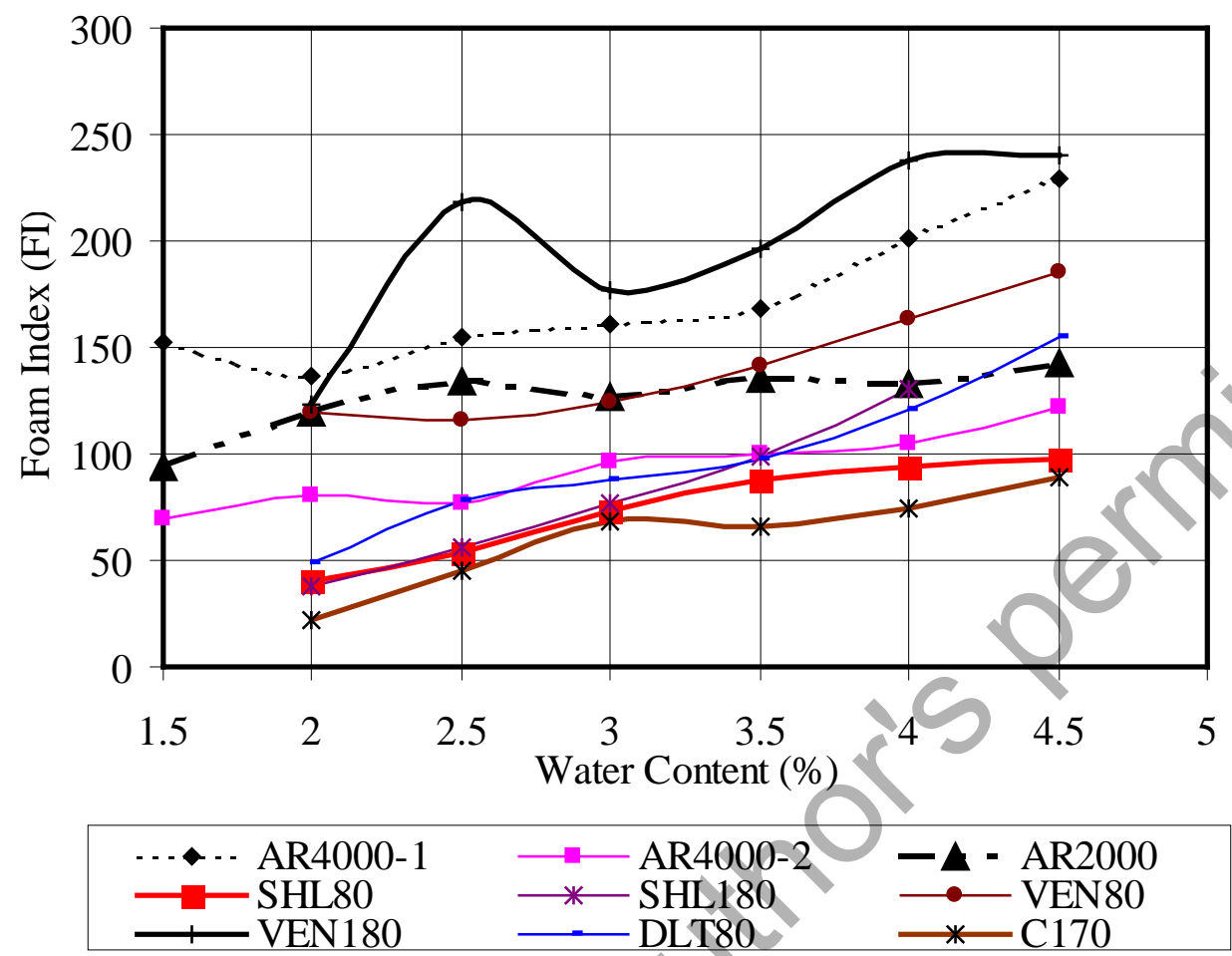

Figure 4 Relationship between Foam Index (FI) and water content (Wc) of the bitumen samples

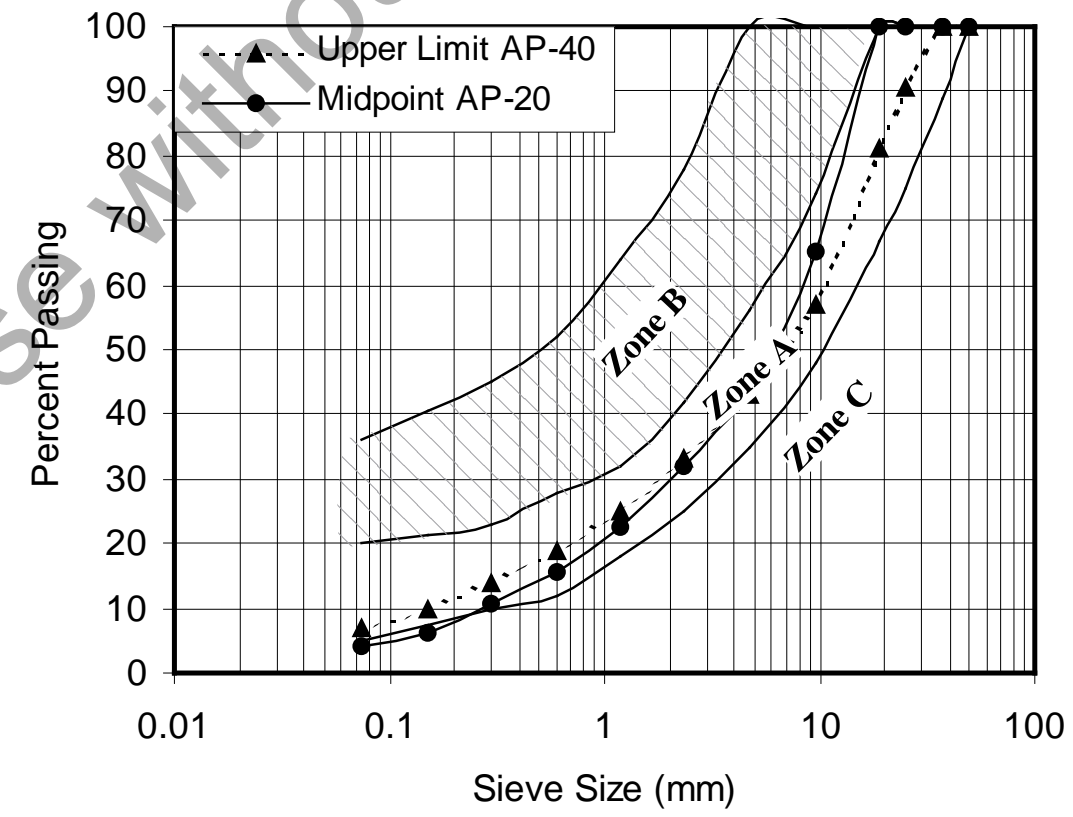

Figure 5 Aggregate gradation of mixes and their suitability for use in foamed bitumen mixes. 


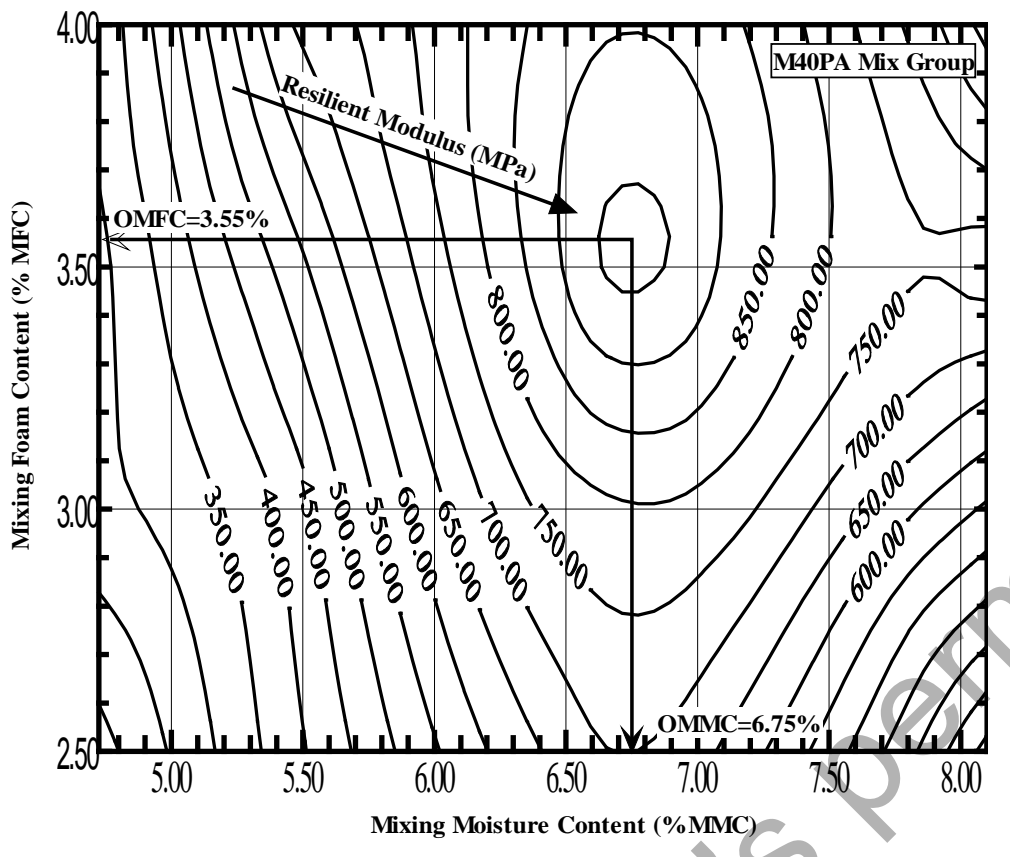

Figure 6 Determining the Optimum Mixing Moisture Content (OMMC\%) and Optimum Mixing Foam Content (OMFC\%) for M40PA.

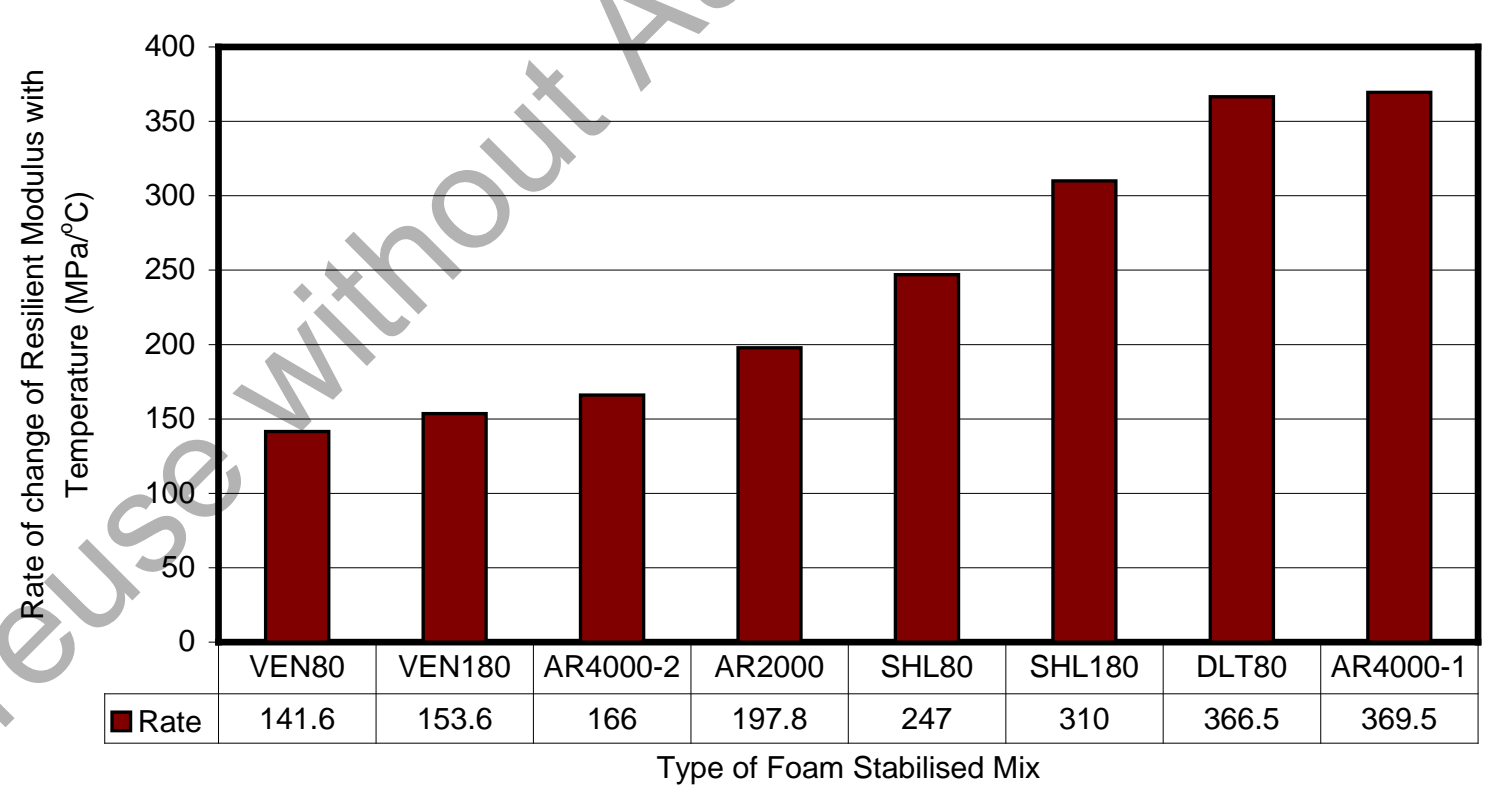

Figure 7 Temperature susceptibility of foam stabilised specimens of the eight bitumen types, shown by rate of change of $M_{r}$ with temperature. 


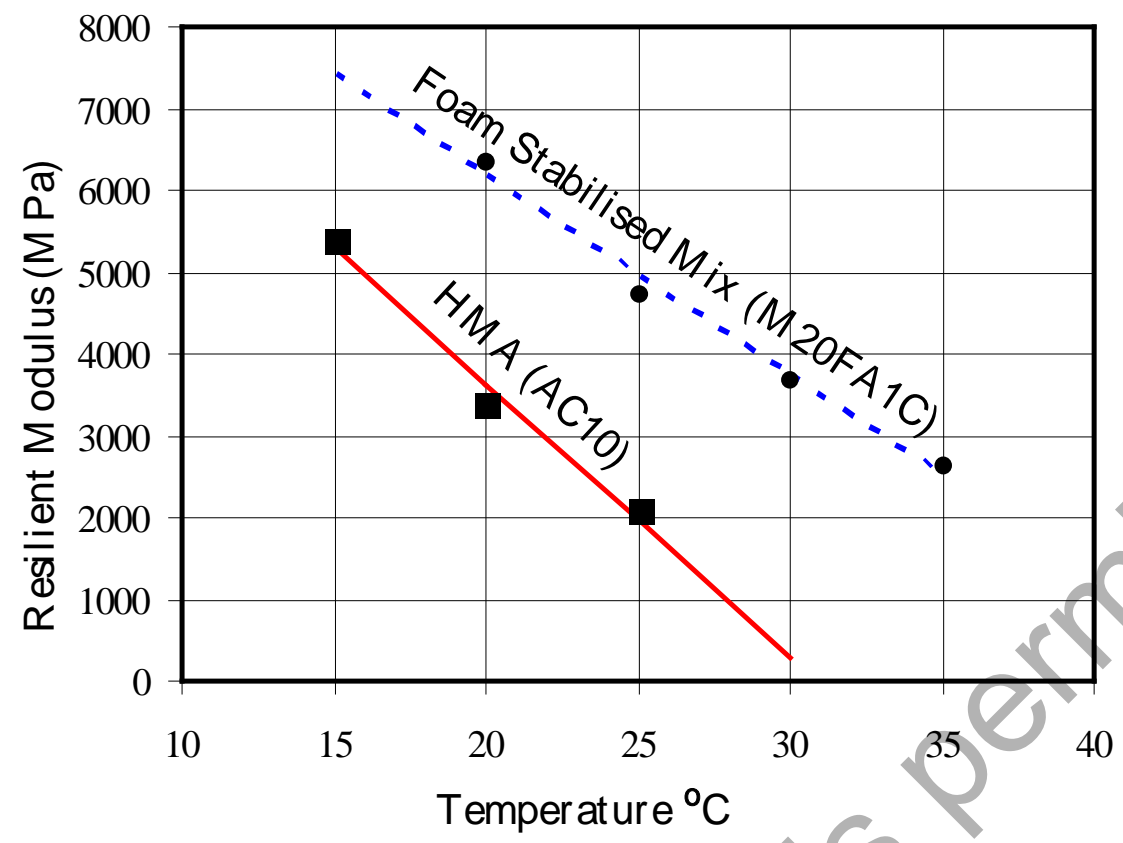

Figure 8 Comparison between the temperature susceptibilities of foam stabilised (M20FA1C) and hot mix asphalt (AC10).

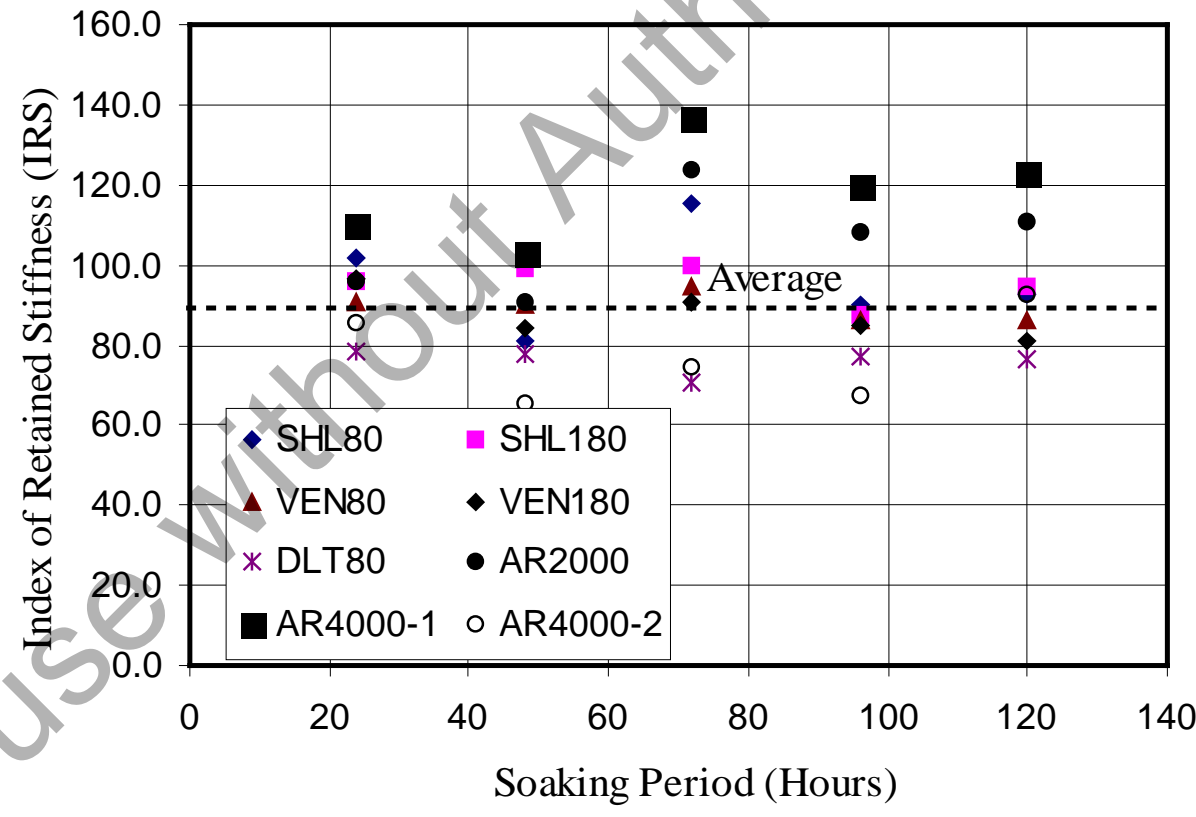

Figure 9 Moisture susceptibility of foam stabilised specimens produced from the eight bitumen types, showing effect of soaking on IRS values, and the average IRS value. 


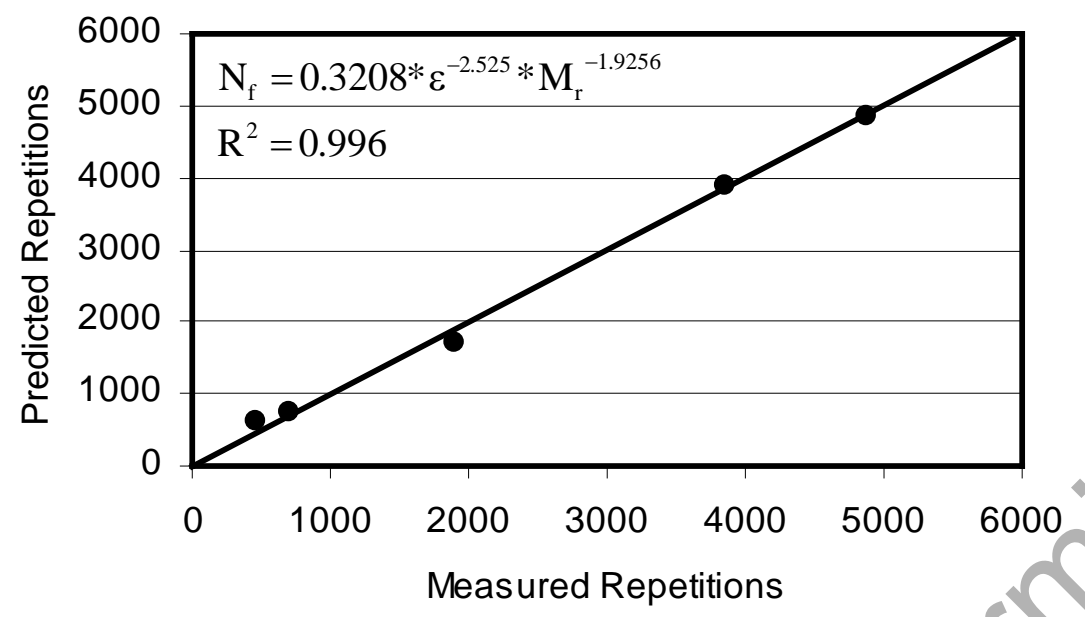

Figure 10 Predicted versus measured number of load repetitions for foamstabilised mix (M20FA1C). 


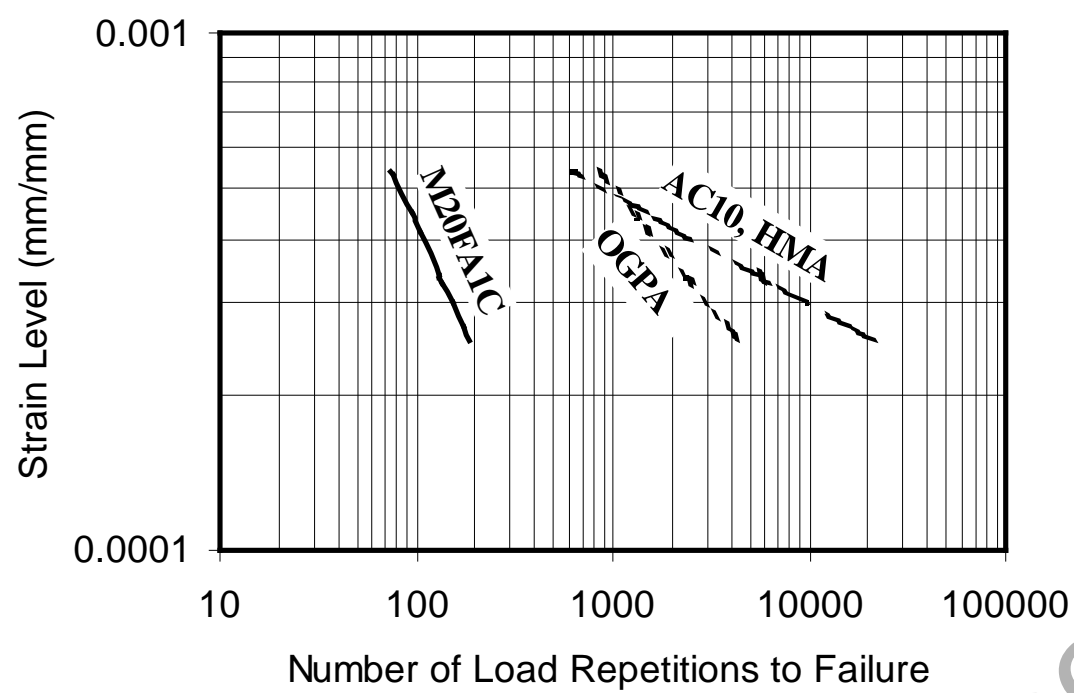

Figure 11 Fatigue life for the 3 different types of mixes M20FA1C, OGPA, and AC10 HMA. 